\title{
A GENERAL MULTI-ATTRIBUTE MULTI-SCALE DECISION MAKING METHOD BASED ON DYNAMIC LINMAP FOR PROPERTY PERCEIVED SERVICE QUALITY EVALUATION
}

\author{
Wen-Jin $\mathrm{ZUO}^{1,3}$, Deng-Feng $\mathrm{LI}^{2 *}$, Gao-Feng $\mathrm{YU}^{3}$ \\ ${ }^{1}$ Zhejiang College, Shanghai University of Finance and Economics, Jinhua, 321013 Zhejiang, China \\ ${ }^{2}$ School of Management and Economics, University of Electronic Science and Technology of China, \\ Chengdu, 611731 Sichuan, China \\ ${ }^{3}$ School of Economics and Management, Fuzhou University, Fuzhou, 350108 Fujian, China
}

Received 31 October 2019; accepted 05 April 2020

\begin{abstract}
The scientific evaluation of property perceived service quality (PPSQ) needs multi-stage, multi-source and large-group perceived information, which is deemed to be the decision problem for dynamic, heterogeneous and large-scale data processing. Aiming at the problem, we propose a general multi-attribute multi-scale (MAMS) method based on the dynamic linear programming technique for multi-dimensional analysis of preference (LINMAP). In the dynamic LINMAP model, the classic MAMS matrix is introduced and extended into a general form. The dynamic LINMAP model is constructed by defining dynamic consistency and dynamic inconsistency. The time series weight is determined by Orness method. The new method adapts to the requirements of modern PPSQ. Finally, we verify the feasibility and effectiveness of dynamic LINMAP method by analyzing a PPSQ evaluation example. The new method improves the traditional PPSQ evaluation, and provides a perspective for large-scale data processing by the classic decision method.
\end{abstract}

Keywords: property perceived service quality, general MAMS method, the dynamic LINMAP model, complex evaluation data.

JEL Classification: C61, H83, M31.

\section{Introduction}

In the 1860s, property service originated in Britain. In 1908, the establishment of CBMO in USA is the first professional property industry organization. In the early 1980s, property management is introduced into mainland China (Deng, 2007). Nowadays, property service industry has become the basic industry of social production and life, and forms a huge market scale. Taking mainland China as an example, the latest statistics show that there are about 105,000 property service enterprises, with about 7112,000 employees. The annual

${ }^{\star}$ Corresponding author. E-mail: lidengfeng@uestc.edu.cn

This is an Open Access article distributed under the terms of the Creative Commons Attribution License (http://creativecommons. org/licenses/by/4.0/), which permits unrestricted use, distribution, and reproduction in any medium, provided the original author and source are credited. 
operating revenue is more than 350 billion Yuan, and the building area of property service reaches 16.45 billion square meter (China Property Management Institute [CPMI], 2018). As the progress of science and technology, property service industry is transforming to modern service industry (Xie, 2012). Because the evaluation information of modern property service quality is multi-source, multi-subject and multi-stage, the traditional evaluation method cannot meet the needs of the complex evaluation environment (Zuo et al., 2019). Therefore, it is of great practical significance to study the property perceived service quality (PPSQ) evaluation method in modern service environment.

The theory of perceived service quality (PSQ) is first proposed in the early 1980s (Gronroos, 1983). Since then, scholars have deeply studied the dimensions and methods of PSQ evaluation. One the one hand, the index system of service quality is based on dimension division. Service quality is divided into technology quality and function quality by Gronroos (1983) in the early stage, and then the components of service quality is expanded into seven dimensions based on the characteristics of employees, customers and services (Gronroos, 2000). U. Lehtinen and J. R. Lehtinen (1982) divide service quality into three dimensions: interactivity, tangibility and company quality. Juran (1986) put forward the five elements of service quality which included technical quality, psychological quality, time quality, relationship quality and moral quality. Hedvyall and Paltschik (1991) take the dimension of service quality as two aspects: the ability and willingness to provide services, and easy access to physical and psychological satisfaction. Ko and Pastore (2004) divide service quality into result quality, physical environment quality, project quality and interaction quality. One the other hand, models and methods are the key to PSQ evaluation. The customer PSQ theory is the foundation of evaluation method in most research results of service quality, in which the SERVQUAL method (Parasuraman et al., 1985) has the greatest impact. The method consists of 5 dimensions, and the measurement value of PSQ is obtained by through a scale containing 22 questions. Aimed at the problem of insufficient empirical test of SERVQUAL model, Cronin and Taylor (1992) propose a PSQ evaluation model based on performance, namely SERVPERF evaluation model. Furthermore, Erto and Vanacore (2002) measure hotel service quality by the probabilistic method based on the KANO model. Mazis (1975) proposes a weighted performance evaluation method, and it solved the problem that the influence of customer perception difference on customer perception service quality evaluation results are ignored in previous evaluation models. Weiner (1986) and Bitner (1990) respectively evaluate the PSQ of customers from psychological perspective, and propose an evaluation method based on attribution model. Brown et al. (1993) believed that the best evaluation method is to directly evaluate the difference between customer perceived performances and service expectations, and proposed the non-difference evaluation method based on SERVQUAL model.

In addition, such as SERVQUAL model (Wu, 2009; Huo, 2010; Han et al., 2013), entropy method (Yang \& Shen, 2012), structural equation model (Huang \& Li, 2013), analytic hierarchy process (Lo et al., 2013; Guo \& Wang, 2014), fuzzy evaluation method (Liao \& Hu, 2017; Shiu et al., 2016), rooted theory (Ming \& Cao, 2019), quality function deployment method (Yao \& Zhong, 2008; Lu, 2018), IVWMM (Liu \& Zuo, 2019) and BP neural network (Liu et al., 2019) are used for PSQ successively. Among them, the empirical analysis method based on SERVQUAL model is the most commonly method in service quality evaluation. The PSQ 
evaluation is used many fields, such as library (Ming \& Cao, 2019), information network (Li, 2010), home-based care (H. Q. Liu \& Q. Liu, 2012), tourism (Qin \& Liu, 2015), logistics (Shi, 2017), distance education (Zhang \& Cao, 2016) and archives (Deng et al., 2018).

Because PSQ and satisfaction have similar dimensions, models and methods, the relevant researches of satisfaction can take as reference for the research of PSQ evaluation method. Research on customer satisfaction begins in the 1960s (Cardozo, 1965). Mesarovic \& Takahara (1972) conduct a systematic research on the satisfaction theory. Subsequently, some scholars discuss the theory of expectation difference and its influence on service performance (Olshavsky \& Miller, 1972; Anderson, 1973). As a macro indicator system to measure the quality of economic output, customer satisfaction index evaluation model includes SCSB, ACSI, ECSI and CCSI (Liu, 2003). In general, the evaluators are limited to the customers in these methods. The structure of evaluation data is single, and there is only one stage of evaluation data. The existing methods cannot meet the requirements of dynamic, heterogeneous and large-scale PPSQ evaluation in modern service environment. Therefore, for solving the above problems, it is necessary to innovate the traditional methods in the theory and practice of PPSQ evaluation.

Decision making method has been widely used in many fields. However, the traditional decision models are difficult to be directly used in large-scale data processing. Some attempts have been made in the research on large group decision making (LGDM). There are two types of existing researches on LGDM: The clustering analysis is used in one type of researches, in which the number of decision makers is usually a few dozen (Chen, 2009; Xu et al., 2017; Zhang \& Fan, 2011; Gou et al., 2018; Liu et al., 2018). Another type of researches introduce multi-attribute multi-scale (MAMS) matrix which is used for data processing in combination with the classic decision-making method (Zhang \& Fan, 2014; Liu et al., 2016; You et al., 2017; Zhang \& Fan, 2011). Although the latter has advantages in large-scale data processing, the method cannot process data with complex structure. There have been several reports on the research of dynamic LGDM methods (Cai et al., 2016; Xu et al., 2014, 2018; $\mathrm{Xu} \& \mathrm{Wu}, 2014)$. However, these research results generally belong to the first type mentioned above and cannot realize large-scale data fusion.

The classic LINMAP method is a famous method which simultaneously process overall preference information and itemized evaluation information (Shocker \& Srinivasan, 1973). It is used for data processing of fuzzy number (Li \& Yang, 2004; Bereketli et al., 2011), intuitionistic fuzzy number ( $\mathrm{Li}, 2008$; Li et al., 2010) and grey numbers (Razavi Hajiagha et al., 2012). It is also used to process heterogeneous information (Wan \& $\mathrm{Li}, 2013$ ), large-scale information (Zuo et al., 2019) and uncertain risk information (Song et al., 2018). However, there is no LINMAP method that can process large-scale, heterogeneous, and dynamic data simultaneously. The LINMAP method has widely applied in invest money selection (Xu et al., 2016), railway project investment (Xue et al., 2018) and supplier evaluation (Song et al., 2018). To sum up, the potential of LINMAP to process the data with complex structure needs to be further explored, and its application field needs to be further expanded.

The contributions of this paper mainly include the following three aspects: (1) We design a PPSQ method based on complex evaluation data. The new method can be used for multi-type of evaluators and multi-stage evaluation data processing. It not only enriches the 
PPSQ evaluation method, but also suitable for complex data processing in modern service. (2) We propose a generalized MAMS method based on the classical MAMS method. Then the generalized MAMS method is used for large-scale heterogeneous data processing. The data processing power of the new method has been greatly improved, which provides a new perspective for decision model constructing of large-scale data processing. (3) We propose a dynamic LINMAP model based on Orness and MAMS methods. The PIS based on the general MAMS matrix is analyzed, and the weight of time series is determined by the Orness method. The dynamic LINMAP model is constructed by defining dynamic consistency and dynamic inconsistency. The new method adapts to the requirement of dynamic evaluation data processing.

The remainder of this paper is organized as follows. Section 1 illustrates the basic problem to be studied, includes some notations used in this article. Section 2 proposes the basic method and principle, includes analysis of time series weights and attributes weights, definition of dynamic consistency and dynamic inconsistency, and construction of dynamic LINMAP model. Section 3 uses the above method to analyze a PPSQ example with dynamic, heterogeneous and large-scale data. Section 4 compares the new method with the traditional LINMAP method, including sensitivity analysis, case analysis, comparison and summaries. Finally, we draw a brief conclusion and prospects the future research.

\section{Description of problem}

\subsection{Definition of general MAMS decision-making}

Decision makers are composed of users and experts. The former make itemized evaluation on different attributes of alternatives, while the latter make overall preference comparison between alternatives. The MAMS decision matrix is used for large-scale data processing in this paper, which is the focus of the problem.

Definition 1 (Zhang \& Fan 2011). If each attribute can be evaluated by the set of scale in the multi-attribute decision making, which is called the MAMS decision making.

In the classic MAMS decision making, each attribute have the same number of scales.

Definition 2. If the number of scale set corresponding to each attribute is not completely the same in the MAMS decision-making, which is called the general MAMS decisionmaking.

\subsection{Some notations and their connotations}

For the sake of the description in this paper, there are some notations are as follows:

- $A=\left\{A_{1}, A_{2}, \ldots, A_{p}\right\}$ denotes the set which is composed of $p$ alternatives, where $A_{k}$ is the $k$ th alternative, $k=1,2, \cdots, p$.

$-\xi=\left(\xi^{1}, \xi^{2}, \ldots, \xi^{q}\right)$ denotes the weight vector of $q$ stages, where $\xi^{t}$ is the weight of the $t$ th stage, $\sum_{t=1}^{q} \xi^{t}=1, \xi^{t} \geq 0, t=1,2, \ldots, q$.

- $C^{t}=\left\{C_{1}^{t}, C_{2}^{t}, \ldots, C_{m}^{t}\right\}$ denotes the set which is composed of $m$ attributes, where $C_{i}^{t}$ is the $i$ th attribute in the $t$ th stage, $i=1,2, \ldots, m$. 
- $\omega^{t}=\left(\omega_{1}^{t}, \omega_{2}^{t}, \ldots, \omega_{m}^{t}\right)$ denotes the corresponding weight vector of $C^{t}$, where $\omega_{i}^{t}$ is the corresponding weight of $C_{i}^{t}, \sum_{i=1}^{m} \omega_{i}^{t}=1, \omega_{i}^{t} \geq 0$.

- $S^{t}=\left\{S_{1}^{t}, S_{2}^{t}, \ldots, S_{m}^{t}\right\}$ denotes the set which is composed of $m$ subsets in the $i$ th stage, where $S_{i}^{t}$ is the $i$ th element of $S^{t}$.

- $S_{i}^{t}=\left\{s_{i 1}^{t}, s_{i 2}^{t}, \ldots, s_{i n_{i}^{t}}^{t}\right\}\left(j=1,2, \ldots, n_{i}^{t}\right)$ denotes the corresponding set of $C_{i}^{t}$, where $s_{i j}^{t}$ is the $j$ th element in $S_{i}^{t}$, and $n_{i}^{t}$ is a natural number which denotes the scale number of the $i$ th attribute in the $t$ th stage. According to the existing researches (Berry et al., 1988; Liao \& Hu, 2017; Yang \& Shen, 2012; Guo, 2014), all elements in $S_{i}^{t}$ form equidistant scale and increasing sequence.

- $u_{i j k}^{t}$ denotes the standardized value of number of users who use $s_{i j}^{t}$ evaluate $A_{k}$ and $C_{i}$ in the $t$ th stage. Table 1 shows the dynamic general MAMS information structure.

- $N_{i j k}^{t}$ denotes the number of users corresponding to $A_{k}$, $s_{i j}^{t}$ and $C_{i}$, where $N^{t}$ denotes the number of users at a certain stage.

- $\Omega=\left\{(k, l) \mid A_{k} \succeq A_{l}\right\}(k, l=1,2, \ldots, p)$ denotes the set where the expert thinks the alternative $A_{k}$ is better than the alternative $A_{l}$.

Table 1. The dynamic general MAMS decision information of users' evaluation

\begin{tabular}{|c|c|c|c|c|c|c|c|c|c|c|c|c|c|}
\hline$C^{t}$ & \multicolumn{5}{|c|}{$C_{1}^{t} / S_{1}^{t}$} & \multicolumn{5}{c|}{$C_{2}^{t} / S_{2}^{t}$} & $\cdots$ & \multicolumn{4}{c|}{$C_{m}^{t} / S_{m}^{t}$} \\
\hline$S^{t}$ & $s_{11}^{t}$ & $s_{12}^{t}$ & $\cdots$ & $s_{1 n_{1}}^{t}$ & $s_{21}^{t}$ & $s_{22}^{t}$ & $\cdots$ & $s_{2 n_{2}}^{t}$ & $\cdots$ & $s_{m 1}^{t}$ & $s_{m 2}^{t}$ & $\cdots$ & $s_{m n_{m}}^{t}$ \\
\hline$A_{1}$ & $u_{111}^{t}$ & $u_{121}^{t}$ & $\cdots$ & $u_{1 n_{1} 1}^{t}$ & $u_{211}^{t}$ & $u_{221}^{t}$ & $\cdots$ & $u_{2 n_{2} 1}^{t}$ & $\cdots$ & $u_{m 11}^{t}$ & $u_{m 21}^{t}$ & $\cdots$ & $u_{m n_{m} 1}^{t}$ \\
\hline$A_{2}$ & $u_{112}^{t}$ & $u_{122}^{t}$ & $\cdots$ & $u_{1 n_{1} 2}^{t}$ & $u_{212}^{t}$ & $u_{222}^{t}$ & $\cdots$ & $u_{2 n_{2} 2}^{t}$ & $\cdots$ & $\cdots$ & $\cdots$ & $\cdots$ & $\cdots$ \\
\hline$\cdots$ & $\cdots$ & $\cdots$ & $\cdots$ & $\cdots$ & $\cdots$ & $\cdots$ & $\cdots$ & $\cdots$ & $\cdots$ & $\cdots$ & $\cdots$ & $\cdots$ & $\cdots$ \\
\hline$A_{p}$ & $u_{11 p}^{t}$ & $u_{12 p}^{t}$ & $\cdots$ & $u_{1 n_{1} p}^{t}$ & $u_{21 p}^{t}$ & $u_{22 p}^{t}$ & $\cdots$ & $u_{2 n_{2} p}^{t}$ & $\cdots$ & $u_{m 1 p}^{t}$ & $u_{m 2 p}^{t}$ & $\cdots$ & $u_{m n_{m} p}^{t}$ \\
\hline
\end{tabular}

\subsection{Key problems and their solving solutions}

According to the above analysis, there are three problems as follows: How to standardize large-scale heterogeneous data effectively? How to improve the LINMAP model according to the requirements of dynamic data processing? How to solve the PPSQ problem based on complex data? The key problem is how to design a decision-making method for dynamic, heterogeneous and large-scale data processing.

We intend to solve the problems according to the following ideas: Firstly, for large-scale heterogeneous data processing, the general MAMS information structure is proposed based on the classical MAMS decision making matrix. For the elements in different scale sets, a standardized method is designed. Secondly, according to the demands of multi-stage information fusion, a dynamic LINMAP model is proposed by defining dynamic consistency and dynamic inconsistency. Lastly, the dynamic LINMAP method is used for PPSQ evaluation, which realizes the synchronous processing of multi-stage and large-scale perceived information. 


\section{The General MAMS decision-making method based on dynamic LINMAP}

\subsection{Standardization of general MAMS decision-making data}

The data in general MAMS decision matrix includes the number of ordinary decision-makers, the scale values, time series weights and attribute weights. Before developing the model and method, we need to standardize these heterogeneous data.

In the general MAMS information structure, the number of decision makers is the same for each alternative and attribute. This is the premise for ensuring that the evaluate value in different alternatives and attributes are comparable. In general dynamic MAMS decisionmaking, the above hypothesis is still valid in the evaluation value at any stage, but it is not necessarily valid in the evaluation value between different stages. Therefore, there exists as follows:

$$
N_{i j}^{t}=\sum_{j=1}^{n_{i}^{t}} N_{i j k}^{t} .
$$

The standardized formula for the number of decision-makers in the general MAMS matrix is as follows:

$$
u_{i j k}^{t}=\frac{N_{i j k}^{t}}{N_{i j}^{t}} .
$$

For the dynamic PPSQ evaluation, the questionnaires are designed in different stages, and they are usually completed by different decision-makers respectively. Therefore, there may be a different scale sets in each questionnaire, and the same scale value in different scale set may has different connotations. In addition, the scale set of different attributes in the same survey may be different.

Example 1. In a set of questionnaires with multi-stages, there are three scale sets and their implications as follows:

$S_{1}^{1}=S_{2}^{1}=S_{3}^{1}=\{1,2\}=\{$ dissatisfied, satisfied $\} ;$

$S_{1}^{2}=S_{2}^{2}=S_{3}^{2}=\{0,1,2,3\}=\{$ not good, indifferent, good, very good $\} ;$

$S_{1}^{3}=S_{2}^{3}=S_{3}^{3}=\{0,1,2,3,4\}=\{$ very dissatisfied, dissatisfied, general dissatisfied,

satisfied, very satisfied $\}$.

Obviously, the scale value 1 denotes "dissatisfied" in $S_{1}^{1}$, "indifferent" in $S_{1}^{2}$ and "dissatisfied" in $S_{1}^{3}$ respectively. Furthermore, the connotation of "dissatisfied" in $S_{1}^{1}$ is different from that of $S_{1}^{3}$.

Therefore, it is necessary to standardize all the scale sets. The basic idea of scale value standardization is to transform all scale sets into the reference set. Determine the reference scale set is the key step. The reference scale set is the set with the most elements. We define it as follows:

Definition 3. Let $\left|S_{i}^{t}\right|$ be the number of elements in the set $S_{i}^{t}$. For any scale set $S_{i}^{t}$ of the general MAMS decision matrix, if there exists:

$$
f\left(S_{i}^{t}\right)=\max _{1 \leq t \leq q 1 \leq i \leq m}\left|S_{i}^{t}\right|,
$$

then the solution $S_{i}^{t *}=\left\{s_{i 1}^{t *}, s_{i 2}^{t *}, \ldots, s_{i i_{i}^{t}}^{t *}\right\}$ is called reference scale set. 

follows:

For any scale in the set $S_{i}^{t}=\left\{s_{i 1}^{t}, s_{i 2}^{t}, \ldots, s_{i n_{i}^{t}}^{t}\right\}$, the standardized processing formula is as

$$
s_{i j}^{t}=s_{i 1}^{t}+\frac{(j-1)\left(s_{i n_{i}^{t}}^{*^{*}}-s_{i 1}^{t^{*}}\right)}{n_{i}^{t}-1},
$$

where $s_{i 1}^{t}=s_{i 1}^{t *}, s_{i n_{i}^{t}}^{t}=s_{i n_{i}^{t}}^{t^{*}}$.

Example 2. The data in Example 1 is still used here.

According to Eq. (3), the reference scale set $S_{1}^{3}=\left\{s_{11}^{3}, s_{12}^{3}, s_{13}^{3}, s_{14}^{3}, s_{15}^{3}\right\}=\{0,1,2,3,4\}$.

According to Eq. (4), the standardized values of the above scale sets are as follows: $S_{1}^{1}=S_{2}^{1}=S_{3}^{1}=\{0,4\}, S_{1}^{2}=S_{2}^{2}=S_{3}^{2}=\{0,1.333,2.667,4\}, S_{1}^{3}=S_{2}^{3}=S_{3}^{3}=\{0,1,2,3,4\}$.

As time series weights and attribute weights are both unknown in advance, we can regard them as standardized unknown numbers. We are going to talk about how to process the two types of data in next section.

\subsection{Analyze the time series weights and attribute weights}

Definition 4 (Yager, 1988). Let $\xi^{t}$ be the weight in the $t$ th stage, there exists $\sum_{t=1}^{q} \xi^{t}=1$, $\xi^{t} \geq 0$. Then, the Orness measure of $\xi^{t}$ is denoted as follows:

$$
\operatorname{Orness}(\xi)=\frac{1}{q-1} \sum_{t=1}^{q}(q-t) \xi^{t}=\gamma, 0 \leq \gamma \leq 1 \text {. }
$$

According to the existing method (Xu, 2009; Yu et al., 2019), the relationship between the weights of adjacent time periods can be further expressed as:

where $0 \leq \gamma \leq 1$.

$$
\xi^{t}-\xi^{t-1}=\frac{(6-12 \gamma)}{q(q+1)},
$$

The analysis results of the stage weight reflect the preference difference of decision makers for the time series. The closer $\gamma$ is to 1 , the more importance decision-maker attach to long-term data. On the contrary, the closer $\gamma$ is to zero, the more importance decision-maker attach to recent data. $\gamma=0.5$ indicates that the importance of each period is the same in the opinion of decision-makers.

Example 3. For a three-stage decision-making, the decision-maker determine $\gamma=0.3$ based on their experience. Combine to $q=3$, Eqs (5) and (6), the time series weights are calculated as follows

$$
\xi=\left(\xi^{1}, \xi^{2}, \xi^{3}\right)=(0.133,0.333,0.533) .
$$

Attribute weights reflect the importance of attributes. Decision-makers usually determine the relation on some attributes based on incomplete information. Early researches showed that the incomplete information structure can be expressed in five forms, includes weak ranking, strict ranking, ranking with multiples, interval form and so on (Podinovski, 2010; Wang et al., 2009). One or more of the above information structures can be used for the expression of the decision makers' preferences. 


\subsection{Dynamic consistency and dynamic inconsistency}

For the classic decision matrix, the positive ideal solution (PIS) is usually row vector. Then, PIS is a multidimensional vector in the dynamic LINMAP method. The PIS based on general MAMS decision matrix in the th stage is denoted as;

$$
u^{+}=\left(u_{i j}^{t+}\right)_{m \times n_{i}^{t}},
$$

where $u_{i j}^{t+}$ is PIS corresponding to different scale $s_{i j}$ and attribute $C_{i}$ in the th stage. For example, $u_{12}^{3+}$ is the PIS of vector $\left(u_{121}^{3}, u_{122}^{3} \ldots, u_{12 p}^{3}\right)$ in the third stage.

Based on the description in Section 1.2, the evaluation information of the alternative $A_{k}$ from all users is denoted as:

where $u_{i k}^{t}=\left(u_{i 1 k}^{t}, u_{i 2 k}^{t}, \ldots, u_{i n_{i}^{t} k}^{t}\right)$.

$$
P\left(A_{k}\right)=\left(u_{i k}^{t}\right)_{q \times m}
$$

Similarly, the evaluation information of $A_{l}$ from all users is denoted as:

where $u_{i l}^{t}=\left(u_{i 1 l}^{t}, u_{i 2 l}^{t}, \ldots, u_{i n_{i}^{t} l}^{t}\right)$.

$$
P\left(A_{l}\right)=\left(u_{i l}^{t}\right)_{q \times m}
$$

If there exists $n_{1}^{t}=n_{2}^{t}=\cdots=n_{m}^{t}$, Eqs (7), (8) and (9) are multidimensional arrays, and the general MAMS decision information structure can be simplified to the classic MAMS decision matrix.

In particular, according to the basic principle of LINMAP method and the requirements of the core model in this paper, the distances defined below are all weighted Euclidean distances.

Definition 5. Let $D_{k}^{t}$ be the dynamic distance square value between the evaluation value of $A_{k}$ and its PIS in the th stage. The dynamic distance square value $D_{k}^{t}$ is denoted as:

$$
\left.D_{k}^{t}=\sum_{i=1}^{m} \omega_{i}^{t}\left[d\left(p\left(A_{k}\right), u^{+}\right)\right)^{2}\right] .
$$

Definition 6. Let $D_{k}$ be the comprehensive dynamic distance square value between the evaluation value of $A_{k}$ and its PIS. The comprehensive dynamic distance square value $D_{k}$ is denoted as:

$$
D_{k}=\sum_{t=1}^{q} \xi^{t} \sum_{i=1}^{m} \omega_{i}^{t}\left[d\left(p\left(A_{k}\right), u^{+}\right)^{2}\right] .
$$

The above equation can be rewritten as:

$$
D_{k}=\sum_{t=1}^{q} \xi^{t} \sum_{i=1}^{m} \sum_{j=1}^{n_{i}^{t}}\left[\omega_{i}^{t}\left(s_{i j}^{t} u_{i j k}^{t}-s_{i j}^{t} u_{i j}^{t+}\right)^{2}\right] .
$$

Similarly, the comprehensive dynamic distance square value $D_{l}$ can be written as:

$$
D_{l}=\sum_{t=1}^{q} \xi^{t} \sum_{i=1}^{m} \sum_{j=1}^{n_{i}^{t}}\left[\omega_{i}^{t}\left(s_{i j}^{t} u_{i j l}^{t}-s_{i j}^{t} u_{i j}^{t+}\right)^{2}\right] .
$$

If $D_{l} \geq D_{k}$, the comprehensive dynamic distance square value of $A_{l}$ is greater than one of $A_{k}$. Then, the evaluation of $A_{k}$ is superior to $A_{l}$. Apparently, the value $\left(\xi^{t}, \omega_{i}^{t}, u_{i j}^{t+}\right)$ determines the ranking order of $A_{k}$ and $A_{l}$. 
According to the above analysis, the dynamic consistency and the dynamic inconsistency between the alternative $A_{k}$ and $A_{l}$ are determined by the relation between the comprehensive dynamic distance square value $D_{k}$ and $D_{l}$.

Definition 7. Let $B^{t}$ be the dynamic inconsistency of the alternative $A_{k}$ and $A_{l}$ in the $t$ th stage, the equation of dynamic inconsistency is denoted as:

$$
B^{t}=\left(D_{l}^{t}-D_{k}^{t}\right)^{-}=\left\{\begin{array}{cc}
D_{k}^{t}-D_{l}^{t} & \left(D_{l}^{t}<D_{k}^{t}\right) \\
0 & \left(D_{l}^{t} \geq D_{k}^{t}\right)
\end{array} .\right.
$$

The above equation can be further simplified for $B^{t}=\max \left(0, D_{k}^{t}-D_{l}^{t}\right)$. Consider the overall preferences of all experts, the comprehensive dynamic inconsistency in the $t$ th stage can be written as

$$
B_{\Omega}^{t}=\sum_{(k, l) \in \Omega}\left(D_{l}^{t}-D_{k}^{t}\right)^{-}=\sum_{(k, l) \in \Omega} \max \left(0, D_{k}^{t}-D_{l}^{t}\right) .
$$

Definition 8. Let $G^{t}$ be the dynamic consistency of the alternative $A_{k}$ and $A_{l}$ in the $t$ th stage, the equation of dynamic consistency is denoted as:

$$
G^{t}=\left(D_{l}^{t}-D_{k}^{t}\right)^{+}=\left\{\begin{array}{cc}
D_{l}^{t}-D_{k}^{t} & \left(D_{l}^{t} \geq D_{k}^{t}\right) \\
0 & \left(D_{l}^{t}<D_{k}^{t}\right)
\end{array} .\right.
$$

The above equation can be further simplified for $G^{t}=\max \left(0, D_{l}^{t}-D_{k}^{t}\right)$. Consider the overall preferences of all experts, the comprehensive dynamic consistency in the $t$ th stage can be written as

$$
G_{\Omega}^{t}=\sum_{(k, l) \in \Omega}\left(D_{l}^{t}-D_{k}^{t}\right)^{+}=\sum_{(k, l) \in \Omega} \max \left(0, D_{l}^{t}-D_{k}^{t}\right) .
$$

According to Eqs (15) and (17), the difference of the comprehensive dynamic consistency and the comprehensive dynamic inconsistency is denoted as:

$$
\begin{gathered}
G_{\Omega}^{t}-B_{\Omega}^{t}=\sum_{(k, l) \in \Omega} \sum_{t=1}^{q}\left(D_{l}^{t}-D_{k}^{t}\right)^{+}-\sum_{(k, l) \in \Omega} \sum_{t=1}^{q}\left(D_{l}^{t}-D_{k}^{t}\right)^{-}= \\
\sum_{(k, l) \in \Omega} \sum_{t=1}^{q}\left[\left(D_{l}^{t}-D_{k}^{t}\right)^{+}-\left(D_{k}^{t}-D_{l}^{t}\right)^{-}\right]=\sum_{(k, l) \in \Omega} \sum_{t=1}^{q}\left[D_{l}^{t}-D_{k}^{t}\right] .
\end{gathered}
$$

\subsection{The dynamic LINMAP model}

In the LINMAP method, the minimum inconsistency is taken as the optimal objective function in the mathematical programming model. Attribute weight and the relationship between consistency and inconsistency are added as constraints. Refer to existing research results (Shocker \& Srinivasan, 1973; Li \& Yang, 2004), the dynamic LINMAP model is denoted as:

$$
\begin{aligned}
& \min \left\{B_{\Omega}^{t}\right\} \\
& \left\{\begin{array}{l}
G_{\Omega}^{t}-B_{\Omega}^{t} \geq h \\
\sum_{i=1}^{m} \omega_{i}^{t}=1, \omega_{i}^{t}>\varepsilon \\
i=1,2, \ldots, m, t=1,2, \ldots, q
\end{array}\right.
\end{aligned}
$$


where $G_{\Omega}^{t}$ and $B_{\Omega}^{t}$ denote the comprehensive dynamic consistency index and the comprehensive dynamic inconsistency index respectively, $h>0$ and $\varepsilon>0$ are given in advance. $h$ makes the comprehensive dynamic consistency greater than the comprehensive dynamic inconsistency. $\varepsilon$ ensures that all attribute weights are greater than zero.

For any pair $(k, l) \in \Omega$, let $\lambda_{k l}=\min \left(0, \sum_{t=1}^{q}\left(D_{l}^{t}-D_{k}^{t}\right)\right)$, it can be written as:

where $\lambda_{k l} \geq 0$.

$$
\lambda_{k l} \leq \sum_{t=1}^{q}\left(D_{l}^{t}-D_{k}^{t}\right),
$$

By combining Eqs (7), (8), (9), (12), (13), (18), (19) and (20), the dynamic LINMAP model is denoted as

$$
\begin{aligned}
& \min \left\{\sum_{(k, l) \in \Omega} \lambda_{k l}\right\} \\
& \left\{\begin{array}{l}
\sum_{(k, l) \in \Omega} \sum_{t=1}^{q} \xi^{t} \sum_{i=1}^{m} \sum_{j=1}^{n_{i}^{t}} \omega_{i}^{t}\left[s_{i j}^{t 2}\left(u_{i j l}^{t}{ }^{2}-u_{i j k}^{t}{ }^{2}\right)+2 u_{i j}^{t+} s_{i j}^{t}\left(u_{i j k}^{t}-u_{i j l}^{t}\right)\right] \geq h \\
\sum_{t=1}^{q} \xi^{t} \sum_{i=1}^{m} \sum_{j=1}^{n_{i}^{t}} \omega_{i}^{t}\left[s_{i j}^{t 2}\left(u_{i j k}^{t}{ }^{2}-u_{i j l}^{t} 2\right)+2 u_{i j}^{t+} s_{i j}^{t}\left(u_{i j l}^{t}-u_{i j k}^{t}\right)\right]+\lambda_{k l} \geq 0 \\
\xi^{t} \in H_{1}, \sum_{t=1}^{q} \xi^{t}=1 \\
\omega_{i}^{t} \in H_{2}, \sum_{i=1}^{m} \omega_{i}^{t}=1 \\
\lambda_{k l}>0,(k, l) \in \Omega \\
i=1,2, \ldots, m, j=1,2, \ldots, n_{i}^{t}, k, l=1,2, \ldots, p, t=1,2, \ldots, q
\end{array},\right.
\end{aligned}
$$

where $H_{1}$ and $H_{2}$ are determined by the method from Section 2.2.

After attribute weights, time series weights and PIS are determined, and the comprehensive dynamic distance square value between any alternative and its PIS are determined by use of Eq. (12) or (13). The ranking order of each alternative is determined according to its distance from PIS.

\subsection{Decision process}

Step 1. Standardize the number of ordinary decision-makers in different attributes, scales and stages by Eqs (1) and (2). Standardize the evaluation scales in different attributes and stages by Eqs (3) and (4).

Step 2. Combine with the $\gamma$ value, Eqs (5) and (6) to determine the time series weight, and analyze the attribute weight by the decision-makers' experience.

Step 3. Analyze the PIS of general MAMS decision matrix by Eq. (7).

Step 4. Collect the overall preferences of experts and determine the preferences set $\Omega$.

Step 5. Determine the total dynamic consistency and the total dynamic inconsistency by Eq. (15) and (17), and construct the dynamic LINMAP model by Eq. (21). 
Step 6. Solve Eq. (21), and determine the final attribute weight by combine with sensitivity analysis.

Step 7. Calculate the comprehensive dynamic distance square value by Eq. (12) or (13), and ranking order.

\section{The PPSQ evaluation based on dynamic information}

\subsection{Introduction to PPSQ evaluation}

The basic data come from successive surveys of different public construction projects. Three surveys were conducted in 2014, 2016 and 2018 respectively. The four evaluation objects include museum $\left(A_{1}\right)$, library $\left(A_{2}\right)$, science museum $\left(A_{3}\right)$ and grand theater $\left(A_{4}\right)$.

In the dynamic PPSQ evaluation, there are two types of decision makers: experts and large-scale visitors. Three experts are invited from university, government and property management association. Property management experts make overall preference comparison on between the property service projects based on macroscopic perspective. Visitors who familiar with four public construction projects simultaneously are selected as general decision makers. Visitor evaluation adopts questionnaire survey in three stages. We used the methods of on-site interview and telephone interview to collect information. The main content of the questionnaire is that visitors evaluate different attributes of different alternatives by use of different scale values. By referring to the PPSQ evaluation practice of property service companies such as VANKE and GREENTOWN, we determine some attributes which composed of attitude $\left(C_{1}\right)$, greening $\left(C_{2}\right)$, cleaning $\left(C_{3}\right)$, facilities $\left(C_{4}\right)$ and safety $\left(C_{5}\right)$. It should be noted that the scale set of three stages are different. The incoherent of the questionnaire survey led to the different scale set. The scale values are determined in advance by the decision-maker respectively. The survey data of three stages is summarized in Table 2.

Table 2. Dynamic distribution of the number of visitor evaluation

Data from the first survey (2014)

\begin{tabular}{|c|c|c|c|c|c|c|c|c|c|c|}
\hline$C^{1}$ & \multicolumn{2}{|c|}{$C_{1}^{1}$} & \multicolumn{2}{c|}{$C_{2}^{1}$} & \multicolumn{2}{c|}{$C_{3}^{1}$} & \multicolumn{2}{c|}{$C_{4}^{1}$} & \multicolumn{2}{c|}{$C_{5}^{1}$} \\
\hline$S^{1}$ & 1 & 2 & 1 & 2 & 1 & 2 & 1 & 2 & 1 & 2 \\
\hline$A_{1}$ & 28 & 17 & 8 & 37 & 37 & 8 & 35 & 10 & 18 & 27 \\
\hline$A_{2}$ & 15 & 30 & 25 & 20 & 30 & 15 & 21 & 24 & 13 & 32 \\
\hline$A_{3}$ & 21 & 24 & 16 & 29 & 37 & 8 & 16 & 29 & 32 & 13 \\
\hline$A_{4}$ & 19 & 26 & 11 & 34 & 36 & 9 & 18 & 27 & 19 & 26 \\
\hline
\end{tabular}

Data from the second survey (2016)

\begin{tabular}{|c|c|c|c|c|c|c|c|c|c|c|c|c|c|c|c|c|c|c|c|c|}
\hline$C^{2}$ & \multicolumn{4}{|c|}{$C_{1}^{2}$} & \multicolumn{4}{|c|}{$C_{2}^{2}$} & \multicolumn{4}{|c|}{$C_{3}^{2}$} & \multicolumn{4}{|c|}{$C_{4}^{2}$} & \multicolumn{4}{|c|}{$C_{5}^{2}$} \\
\hline$S^{2}$ & 0 & 1 & 2 & 3 & 0 & 1 & 2 & 3 & 0 & 1 & 2 & 3 & 0 & 1 & 2 & 3 & 0 & 1 & 2 & 3 \\
\hline$A_{1}$ & 16 & 30 & 25 & 25 & 14 & 26 & 44 & 12 & 18 & 26 & 41 & 11 & 4 & 39 & 38 & 15 & 8 & 37 & 41 & 10 \\
\hline$A_{2}$ & 5 & 36 & 19 & 36 & 5 & 11 & 76 & 4 & 15 & 39 & 34 & 8 & 12 & 46 & 28 & 10 & 8 & 46 & 32 & 10 \\
\hline$A_{3}$ & 8 & 36 & 33 & 19 & 14 & 24 & 57 & 1 & 15 & 60 & 18 & 3 & 60 & 31 & 5 & 0 & 14 & 38 & 39 & 5 \\
\hline$A_{4}$ & 6 & 32 & 28 & 30 & 8 & 10 & 75 & 3 & 13 & 26 & 41 & 16 & 5 & 26 & 52 & 13 & 4 & 26 & 42 & 24 \\
\hline
\end{tabular}


Data from the third survey (2018)

\begin{tabular}{|c|c|c|c|c|c|c|c|c|c|c|c|c|c|c|c|c|c|c|c|c|c|c|c|c|c|}
\hline$C^{3}$ & \multicolumn{5}{|c|}{$C_{1}^{3}$} & \multicolumn{5}{|c|}{$C_{2}^{3}$} & \multicolumn{5}{|c|}{$C_{3}^{3}$} & \multicolumn{5}{|c|}{$C_{4}^{3}$} & \multicolumn{5}{|c|}{$C_{5}^{3}$} \\
\hline \begin{tabular}{|l|}
$S^{3}$ \\
\end{tabular} & 0 & 1 & 2 & 3 & 4 & 0 & 1 & 2 & 3 & 4 & 0 & 1 & 2 & 3 & 4 & 0 & 1 & 2 & 3 & 4 & 0 & 1 & 2 & 3 & 4 \\
\hline$A_{1}$ & 3 & 38 & 49 & 12 & 2 & 5 & 35 & 45 & 18 & 1 & 5 & 33 & 42 & 22 & 2 & 7 & 38 & 46 & 12 & 1 & 2 & 31 & 58 & 11 & 2 \\
\hline$A_{2}$ & 12 & 51 & 32 & 7 & 2 & 5 & 50 & 38 & 8 & 3 & 7 & 49 & 38 & 9 & 1 & 10 & 48 & 36 & 9 & 1 & 4 & 48 & 43 & 9 & 0 \\
\hline$A_{3}$ & 20 & 40 & 37 & 6 & 1 & 15 & 50 & 31 & 7 & 1 & 15 & 38 & 42 & 7 & 2 & 13 & 49 & 35 & 6 & 1 & 12 & 45 & 33 & 12 & 2 \\
\hline \begin{tabular}{|l|}
$A_{4}$ \\
\end{tabular} & 7 & 25 & 59 & 12 & 1 & 6 & 37 & 39 & 20 & 2 & 7 & 19 & 56 & 20 & 2 & 6 & 28 & 46 & 22 & 2 & 9 & 22 & 49 & 19 & 5 \\
\hline
\end{tabular}

\subsection{Analysis process of dynamic PPSQ evaluation}

According to the process in Section 2.5, the method in Section 2.4 and the data in Section 3.1 , the PPSQ evaluation based on dynamic information is analyzed as follows.

Step 1. Standardize the visitors' number of different scales, attributes and projects by Eqs (1) and (2). Standardize the different scale sets by Eqs (3) and (4). The results of standardized scale value are as follows:

$$
\begin{aligned}
& S_{1}=\{1,2\}=\{0,4\} \\
& S_{2}=\{0,1,2,3\}=\{0,1.333,2.667,4\} \\
& S_{3}=\{0,1,2,3,4\}=\{0,1,2,3,4\} .
\end{aligned}
$$

The standardized form corresponding to Table 2 is shown in Table 3.

Table 3. Standardization value of dynamic distribution of visitor evaluation

Data from the first survey (2014)

\begin{tabular}{|c|c|c|c|c|c|c|c|c|c|c|c|c|c|c|c|c|c|c|c|c|}
\hline$C^{2}$ & \multicolumn{4}{|c|}{$C_{1}^{2}$} & \multicolumn{4}{|c|}{$C_{2}^{2}$} & \multicolumn{4}{|c|}{$C_{3}^{2}$} & \multicolumn{4}{|c|}{$C_{4}^{2}$} & \multicolumn{4}{|c|}{$C_{5}^{2}$} \\
\hline$S^{2}$ & 0 & 1.333 & \begin{tabular}{|l|}
2.667 \\
\end{tabular} & 4 & 0 & 1.333 & 2.667 & 4 & 0 & 1.333 & 2.667 & 4 & 0 & 1.333 & \begin{tabular}{|l|}
2.667 \\
\end{tabular} & 4 & 0 & 1.333 & \begin{tabular}{|l|}
2.667 \\
\end{tabular} & 4 \\
\hline$A_{1}$ & 0.167 & 0.313 & 0.260 & 0.260 & 0.146 & 0.271 & 0.458 & 0.125 & 0.188 & 0.271 & 0.427 & 0.115 & 0.042 & 0.406 & 0.396 & 0.156 & 0.083 & 0.385 & 0.427 & 0.104 \\
\hline$A_{2}$ & 0.052 & 0.375 & 0.198 & 0.375 & 0.052 & 0.115 & 0.792 & 0.042 & 0.156 & 0.406 & 0.354 & 0.083 & 0.125 & 0.479 & 0.292 & 0.104 & 0.083 & 0.479 & 0.333 & 0.104 \\
\hline$A_{3}$ & 0.083 & 0.375 & 0.344 & 0.198 & 0.146 & 0.250 & 0.594 & 0.010 & 0.156 & 0.625 & 0.188 & 0.031 & 0.625 & 0.323 & 0.052 & 0.000 & 0.146 & 0.396 & 0.406 & 0.052 \\
\hline$A_{4}$ & 0.063 & 0.333 & 0.292 & 0.313 & 0.083 & 0.104 & 0.781 & 0.031 & 0.135 & 0.271 & 0.427 & 0.167 & 0.052 & 0.271 & 0.542 & 0.135 & 0.042 & 0.271 & 0.438 & 0.250 \\
\hline
\end{tabular}

\begin{tabular}{|c|c|c|c|c|c|c|c|c|c|c|}
\hline$C^{1}$ & \multicolumn{2}{|c|}{$C_{1}^{1}$} & \multicolumn{2}{c|}{$C_{2}^{1}$} & \multicolumn{2}{c|}{$C_{3}^{1}$} & \multicolumn{2}{c|}{$C_{4}^{1}$} & \multicolumn{2}{c|}{$C_{5}^{1}$} \\
\hline$S^{1}$ & 0 & 4 & 0 & 4 & 0 & 4 & 0 & 4 & 0 & 4 \\
\hline$A_{1}$ & 0.622 & 0.378 & 0.178 & 0.822 & 0.822 & 0.178 & 0.778 & 0.222 & 0.400 & 0.600 \\
\hline$A_{2}$ & 0.333 & 0.667 & 0.556 & 0.444 & 0.667 & 0.333 & 0.467 & 0.533 & 0.289 & 0.711 \\
\hline$A_{3}$ & 0.467 & 0.533 & 0.356 & 0.644 & 0.822 & 0.178 & 0.356 & 0.644 & 0.711 & 0.289 \\
\hline$A_{4}$ & 0.422 & 0.578 & 0.244 & 0.756 & 0.800 & 0.200 & 0.400 & 0.600 & 0.422 & 0.578 \\
\hline
\end{tabular}

Data from the second survey (2016) 
Data from the third survey (2018)

\begin{tabular}{|c|c|c|c|c|c|c|c|c|c|c|c|c|c|c|c|c|c|c|c|c|c|c|c|c|c|}
\hline$C^{3}$ & \multicolumn{9}{|c|}{$C_{1}^{3}$} & \multicolumn{5}{c|}{$C_{2}^{3}$} & \multicolumn{5}{c|}{$C_{3}^{3}$} & \multicolumn{5}{c|}{$C_{5}^{3}$} \\
\hline$S^{3}$ & 0 & 1 & 2 & 3 & 4 & 0 & 1 & 2 & 3 & 4 & 0 & 1 & 2 & 3 & 4 & 0 & 1 & 2 & 3 & 4 & 0 & 1 & 2 & 3 & 4 \\
\hline$A_{1}$ & 0.029 & 0.365 & 0.471 & 0.115 & 0.019 & 0.048 & 0.337 & 0.433 & 0.173 & 0.010 & 0.048 & 0.317 & 0.404 & 0.212 & 0.019 & 0.067 & 0.365 & 0.442 & 0.115 & 0.010 & 0.019 & 0.298 & 0.558 & 0.106 & 0.019 \\
\hline$A_{2}$ & 0.115 & 0.490 & 0.308 & 0.067 & 0.019 & 0.048 & 0.48 & 0.365 & 0.077 & 0.029 & 0.067 & 0.471 & 0.365 & 0.087 & 0.010 & 0.096 & 0.462 & 0.346 & 0.087 & 0.010 & 0.038 & 0.462 & 0.413 & 0.087 & 0.000 \\
\hline$A_{3}$ & 0.192 & 0.385 & 0.356 & 0.058 & 0.010 & 0.144 & 0.481 & 0.298 & 0.067 & 0.010 & 0.144 & 0.365 & 0.404 & 0.067 & 0.019 & 0.125 & 0.471 & 0.337 & 0.058 & 0.010 & 0.115 & 0.433 & 0.317 & 0.115 & 0.019 \\
\hline$A_{4}$ & 0.067 & 0.240 & 0.567 & 0.115 & 0.010 & 0.058 & 0.356 & 0.375 & 0.192 & 0.019 & 0.067 & 0.183 & 0.538 & 0.192 & 0.019 & 0.058 & 0.269 & 0.442 & 0.212 & 0.019 & 0.087 & 0.212 & 0.471 & 0.183 & 0.048 \\
\hline
\end{tabular}

Step 2. According to the principal in Section 2.2 and decision-makers' experience, we analyze the series weights and the attribute weights of PPSQ.

$\gamma=0.3$ is determined by property management experts' experience, and there exists $q=$ 3 in a three stages' survey. According to Eqs (5) and (6), three stages' weights are determined as follows:

$$
H_{1}=\left(\xi^{1}, \xi^{2}, \xi^{3}\right)=(0.133,0.333,0.533) .
$$

This example assumes that property management experts have the same preference on all attributes in different stages. Summarizing the experts' preferences for all attributes, the attribute weights are determined as follows:

$$
\begin{aligned}
H_{2}= & \left\{\left(\omega_{1}^{t}, \omega_{2}^{t}, \omega_{3}^{t}, \omega_{4}^{t}, \omega_{5}^{t}\right) \mid \omega_{1}^{t} \leq 0.8 \omega_{2}^{t}, \omega_{2}^{t}-\omega_{3}^{t} \leq 0.15, \omega_{2}^{t}-\omega_{3}^{t} \geq 0.001,\right. \\
& \left.\omega_{4}^{t} \leq 0.25, \omega_{4}^{t} \geq 0.01, \omega_{1}^{t}-\omega_{2}^{t} \leq \omega_{4}^{t}-\omega_{5}^{t}\right\} .
\end{aligned}
$$

Step 3. Since the scale value is positive correlation with PPSQ, the maximum (minimum) value of scale correspond to biggest (smallest) value of PPSQ. According to the practice of property service, the reference point is determined to be half of the sum of the maximum scale value and the minimum scale value. The reference points divide scale values into two categories: the smaller scale values and the larger scale values. Since the total number of visitors who evaluate each project is the same in a certain stage, there are some principles as follows: the fewer the number of visitors using the smaller scale value, the better the property service quality and vice versa; the fewer the number of visitors using greater scale values, the lower the quality of the property service and vice versa. By combining the above rules and related data, the calculation results of PIS are shown in Table 4.

Step 4. Collect the overall preferences of property management experts and determine the preferences set $\Omega$. Their preference order is summarized as follows:

$$
\Omega=\{(1,2),(2,3),(4,1),(4,3)\},
$$

where $(k, l)$ denotes the public property service project $A_{k}$ is better than $A_{l}$ in the opinion of experts. For example, the array $(1,2)$ denotes the property service project $A_{1}$ is better than $A_{2}$ in the opinion of experts.

Step 5. Determine the dynamic consistency and dynamic inconsistency, and construct the dynamic LINMAP model of the PPSQ evaluation data with 3 stages. By combining Eqs (20), (21), (25), (26), (27) and the data from Tables 3 and 4, the dynamic LINMAP model of PPSQ can be expressed as follows 


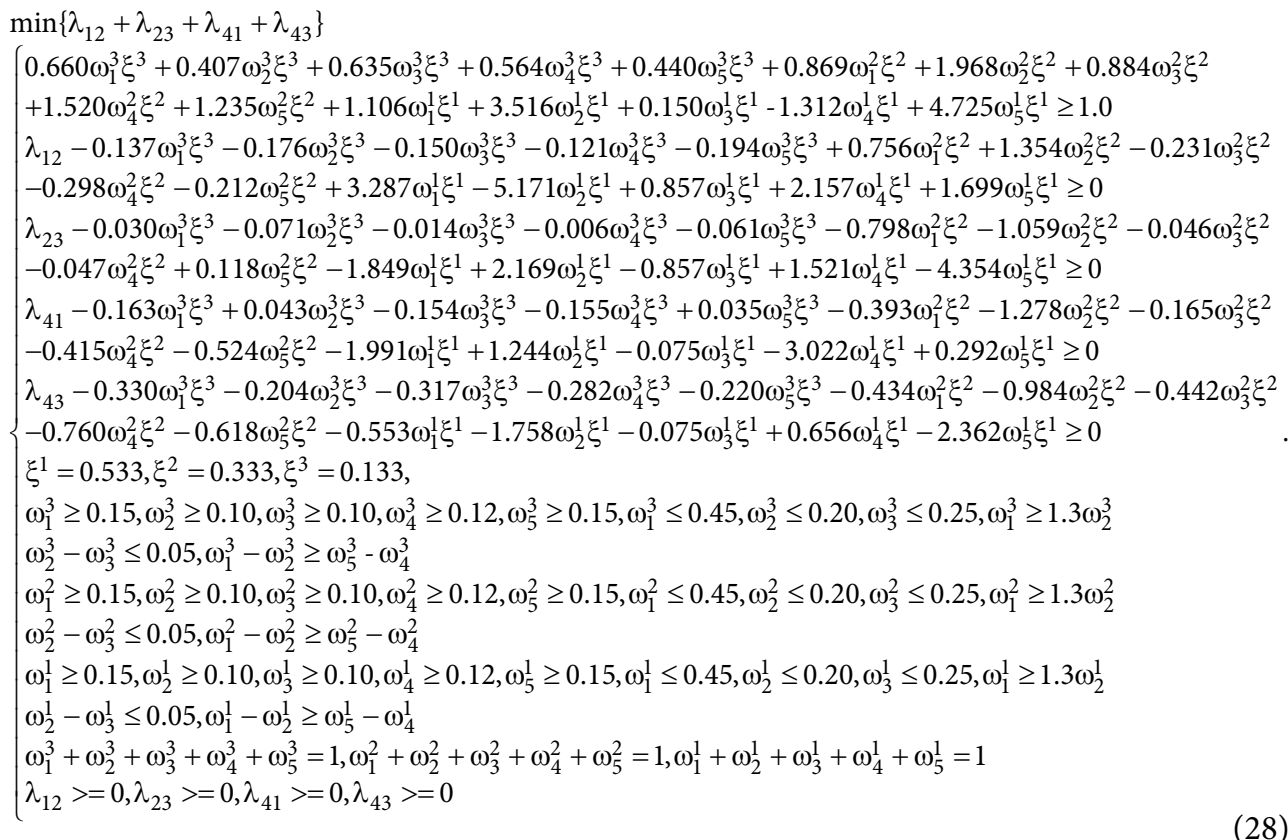

Step 6. Calculate Eq. (28) by LINGO 11.0. When $h=1.0$, the calculation result of attribute weight is determined as follows:

$$
\begin{aligned}
& \left(\omega_{1}^{1}, \omega_{2}^{1}, \omega_{3}^{1}, \omega_{4}^{1}, \omega_{5}^{1}\right)=(0.441,0.150,0.100,0.120,0.189) ; \\
& \left(\omega_{1}^{2}, \omega_{2}^{2}, \omega_{3}^{2}, \omega_{4}^{2}, \omega_{5}^{2}\right)=(0.150,0.100,0.100,0.500,0.150) ; \\
& \left(\omega_{1}^{3}, \omega_{2}^{3}, \omega_{3}^{3}, \omega_{4}^{3}, \omega_{5}^{3}\right)=(0.450,0.100,0.180,0.120,0.150) .
\end{aligned}
$$

Table 4. The PIS of different attributes, scales and stages

Data from the first survey (2014)

\begin{tabular}{|c|c|c|c|c|c|c|c|c|c|c|c|c|c|c|c|c|c|c|c|}
\hline$C^{2}$ & \multicolumn{4}{|c|}{$C_{1}^{2}$} & \multicolumn{4}{|c|}{$C_{2}^{2}$} & \multicolumn{4}{|c|}{$C_{3}^{2}$} & \multicolumn{4}{|c|}{$C_{4}^{2}$} & \multicolumn{3}{|c|}{$C_{5}^{2}$} \\
\hline \begin{tabular}{|l|}
$S_{2}$ \\
\end{tabular} & 0 & 1.333 & 2.667 & 4 & 0 & 1.333 & 2.667 & 4 & 0 & 1.333 & 2.667 & 4 & 0 & 1.333 & 2.667 & 4 & 0 & \begin{tabular}{|l|l|}
1.333 & 2.667 \\
\end{tabular} & 4 \\
\hline PIS & 0.052 & 0.313 & 0.344 & 0.375 & 0.052 & 0.104 & 0.792 & 0.125 & 0.135 & 0.271 & 0.427 & 0.167 & 0.042 & 0.271 & 0.542 & 0.156 & 0.042 & \begin{tabular}{|l|l|l|}
0.271 & 0.438 \\
\end{tabular} & 0.250 \\
\hline
\end{tabular}

\begin{tabular}{|c|c|c|c|c|c|c|c|c|c|c|}
\hline$C^{1}$ & \multicolumn{2}{|c|}{$C_{1}^{1}$} & \multicolumn{2}{c|}{$C_{2}^{1}$} & \multicolumn{2}{c|}{$C_{3}^{1}$} & \multicolumn{2}{c|}{$C_{4}^{1}$} & \multicolumn{2}{c|}{$C_{5}^{1}$} \\
\hline$S_{1}$ & 0 & 4 & 0 & 4 & 0 & 4 & 0 & 4 & 0 & 4 \\
\hline$P I S$ & 0.333 & 0.667 & 0.178 & 0.822 & 0.667 & 0.333 & 0.356 & 0.644 & 0.289 & 0.711 \\
\hline
\end{tabular}

Data from the second survey (2016)

\begin{tabular}{|c|c|c|c|c|c|c|c|c|c|c|c|c|c|c|c|c|c|c|c|c|c|c|c|c|c|}
\hline$C^{3}$ & & & $C_{1}^{3}$ & & & & & $C_{2}^{3}$ & & & & & $C_{3}^{3}$ & & & & & $C_{4}^{3}$ & & & & & $C_{5}^{3}$ & & \\
\hline$s_{3}$ & 0 & 1 & 2 & 3 & 4 & 0 & 1 & 2 & 3 & 4 & 0 & 1 & 2 & 3 & 4 & 0 & 1 & 2 & 3 & 4 & 0 & 1 & 2 & 3 & 4 \\
\hline PIS & 0.029 & 0.240 & $0.567 \mid$ & 0.115 & 0.019 & 0.048 & 0.337 & 0.433 & 0.192 & 0.029 & 0.048 & 0.183 & 0.538 & 0.212 & 0.019 & 0.058 & \begin{tabular}{|c|}
0.269 \\
\end{tabular} & 0.442 & 0.212 & 0.019 & 0.019 & 0.212 & 0.558 & 0.183 & 0.048 \\
\hline
\end{tabular}

Data from the third survey (2018) 
Step 7. By use of Eq. (12) and the related data, the dynamic comprehensive value of the weighted Euclidean distance square of all property service projects are calculated as follows:

$$
\begin{aligned}
& D\left(A_{1}\right)=0.066 ; \\
& D\left(A_{2}\right)=0.138 ; \\
& D\left(A_{3}\right)=0.242 ; \\
& D\left(A_{4}\right)=0.008 .
\end{aligned}
$$

According to the analysis in Section 2.3, the smaller the comprehensive distance, the better the alternative. By combining the above rule and the comprehensive value of each project, the ranking order is determined as:

$$
A_{4} \succ A_{1} \succ A_{2} \succ A_{3}
$$

\section{Comparison and analysis}

\subsection{Sensitivity analysis}

Because consistency is greater than inconsistency in the LINMAP model, there exists $h>0$. And because $h>1.0$, there is no feasible solution to Eq. (28). Therefore, we take 0.1 as the gradient and take different values between 0 and 1.0, and solve the calculation Eq. (28) (36). Table 5 summarizes the comprehensive value and ranking order of all projects.

As can be seen from Table 5, the comprehensive value of the four projects remains the same when $h \in[0.1,0.8]$, and the comprehensive value of the four projects has some changes when $h \in[0.9,1.0]$. However, the ranking order of all projects remains still the same when $h \in[0.1,1.0]$.

Because there is no empirical analysis of $h$ value in the existing LINMAP research results (Shocker \& Srinivasan, 1973; Li \& Yang, 2004; Bereketli et al., 2011; Li, 2008; Li et al., 2010; Wan \& Li, 2013; Lv \& Li, 2004), we combine the general practice and the experience of decision-makers to determine $h=1.0$. Furthermore, we calculate the comprehensive value

Table 5. The calculated results of all projects in different $h$ values

\begin{tabular}{|c|c|c|c|c|c|}
\hline$h$ & $D\left(A_{1}\right)$ & $D\left(A_{2}\right)$ & $D\left(A_{3}\right)$ & $D\left(A_{4}\right)$ & Ranking order \\
\hline 0.1 & 0.070 & 0.118 & 0.208 & 0.009 & $A_{4} \succ A_{1} \succ A_{2} \succ A_{3}$ \\
\hline 0.2 & 0.070 & 0.118 & 0.208 & 0.009 & $A_{4} \succ A_{1} \succ A_{2} \succ A_{3}$ \\
\hline 0.3 & 0.070 & 0.118 & 0.208 & 0.009 & $A_{4} \succ A_{1} \succ A_{2} \succ A_{3}$ \\
\hline 0.4 & 0.070 & 0.118 & 0.208 & 0.009 & $A_{4} \succ A_{1} \succ A_{2} \succ A_{3}$ \\
\hline 0.5 & 0.070 & 0.118 & 0.208 & 0.009 & $A_{4} \succ A_{1} \succ A_{2} \succ A_{3}$ \\
\hline 0.6 & 0.070 & 0.118 & 0.208 & 0.009 & $A_{4} \succ A_{1} \succ A_{2} \succ A_{3}$ \\
\hline 0.7 & 0.070 & 0.118 & 0.208 & 0.009 & $A_{4} \succ A_{1} \succ A_{2} \succ A_{3}$ \\
\hline 0.8 & 0.070 & 0.118 & 0.208 & 0.009 & $A_{4} \succ A_{1} \succ A_{2} \succ A_{3}$ \\
\hline 0.9 & 0.069 & 0.119 & 0.208 & 0.009 & $A_{4} \succ A_{1} \succ A_{2} \succ A_{3}$ \\
\hline 1.0 & 0.066 & 0.138 & 0.242 & 0.008 & $A_{4} \succ A_{1} \succ A_{2} \succ A_{3}$ \\
\hline
\end{tabular}


of three stages and the ranking order of four projects respectively when $h=1.0$, and the ranking orders of three stages are as follows: $A_{4} \succ A_{2} \succ A_{3} \succ A_{1}, A_{4} \succ A_{1} \succ A_{2} \succ A_{3}$ and $A_{4} \succ A_{1} \succ A_{3} \succ A_{2}$.

\subsection{PPSQ evaluation based on the traditional LINMAP method}

As the LINMAP method based on the classic MAMS matrix (Zuo et al., 2019) is the closest to the new method of this paper in the traditional LINMAP researches, we take it as the representative of the traditional LINMAP method. In order to summarize the characteristics of the new method, the traditional LINMAP method is used to analyze the dynamic PPSQ example. Since the traditional LINMAP method cannot process the data from three stages at the same time, we will analyze the data of each stage respectively.

Using the evaluation data of first stage in Section 3, the traditional LINMAP model based on the first-stage PPSQ data can be denoted as

$$
\begin{aligned}
& \min \left\{\lambda_{12}+\lambda_{23}+\lambda_{41}+\lambda_{43}\right\} \\
& \left\{\begin{array}{l}
1.106 \omega_{1}^{1}+3.516 \omega_{2}^{1}+0.150 \omega_{3}^{1}+1.312 \omega_{4}^{1}-4.725 \omega_{5}^{1} \geq h \\
\lambda_{12}+\left(3.287 \omega_{1}^{1}-5.171 \omega_{2}^{1}+0.857 \omega_{3}^{1}+2.157 \omega_{4}^{1}+1.699 \omega_{5}^{1}\right) \geq 0 \\
\lambda_{23}+\left(-1.849 \omega_{1}^{1}+2.169 \omega_{2}^{1}-0.857 \omega_{3}^{1}+1.521 \omega_{4}^{1}-4.354 \omega_{5}^{1}\right) \geq 0 \\
\lambda_{41}+\left(-1.991 \omega_{1}^{1}+1.244 \omega_{2}^{1}-0.075 \omega_{3}^{1}-3.022 \omega_{4}^{1}+0.292 \omega_{5}^{1}\right) \geq 0 \\
\lambda_{43}+\left(-0.553 \omega_{1}^{1}-1.758 \omega_{2}^{1}-0.075 \omega_{3}^{1}+0.656 \omega_{4}^{1}-2.362 \omega_{5}^{1}\right) \geq 0 \\
\lambda_{12}>=0, \lambda_{23}>=0, \lambda 41>=0, \lambda_{43}>=0 \\
\omega_{1}^{1} \geq 0.15, \omega_{2}^{1} \geq 0.1, \omega_{3}^{1} \geq 0.1, \omega_{4}^{1} \geq 0.12, \omega_{5}^{1} \geq 0.15, \omega_{1}^{1} \leq 0.45, \omega_{2}^{1} \leq 0.2 \\
\omega_{3}^{1} \leq 0.25, \omega_{1}^{1} \geq 1.3 \omega_{2}^{1}, \omega_{2}^{1}-\omega_{3}^{1} \leq 0.05, \omega_{1}^{1}-\omega_{2}^{1} \geq \omega_{5}^{1}-\omega_{4}^{1} \\
\omega_{1}^{1}+\omega_{2}^{1}+\omega_{3}^{1}+\omega_{4}^{1}+\omega_{5}^{1}=1
\end{array}\right.
\end{aligned}
$$

Using the evaluation data of second stage in Section 3, the traditional LINMAP model based on the second-stage PPSQ data can be denoted as

$$
\begin{aligned}
& \min \left\{\lambda_{12}+\lambda_{23}+\lambda_{41}+\lambda_{43}\right\} \\
& \left\{\begin{array}{l}
0.869 \omega_{1}^{2}+1.968 \omega_{2}^{2}+0.884 \omega_{3}^{2}+1.520 \omega_{4}^{2}+1.235 \omega_{5}^{2} \geq h \\
\lambda_{12}+\left(0.756 \omega_{1}^{2}+1.354 \omega_{2}^{2}-0.231 \omega_{3}^{2}-0.298 \omega_{4}^{2}-0.212 \omega_{5}^{2}\right) \geq 0 \\
\lambda_{23}+\left(-0.798 \omega_{1}^{2}-1.059 \omega_{2}^{2}-0.046 \omega_{3}^{2}-0.047 \omega_{4}^{2}+0.118 \omega_{5}^{2}\right) \geq 0 \\
\lambda_{41}+\left(-0.393 \omega_{1}^{2}-1.278 \omega_{2}^{2}-0.165 \omega_{3}^{2}-0.415 \omega_{4}^{2}-0.524 \omega_{5}^{2}\right) \geq 0 \\
\lambda_{43}+\left(-0.434 \omega_{1}^{2}-0.984 \omega_{2}^{2}-0.442 \omega_{3}^{2}-0.760 \omega_{4}^{2}-0.618 \omega_{5}^{2}\right) \geq 0 \\
\lambda_{12}>=0, \lambda_{23}>=0, \lambda_{41}>=0, \lambda_{43}>=0 \\
\omega_{1}^{2} \geq 0.15, \omega_{2}^{2} \geq 0.1, \omega_{3}^{2} \geq 0.1, \omega_{4}^{2} \geq 0.12, \omega_{5}^{2} \geq 0.15, \omega_{1}^{2} \leq 0.45, \omega_{2}^{2} \leq 0.2 \\
\omega_{3}^{2} \leq 0.25, \omega_{1}^{2} \geq 1.3 \omega_{2}^{2}, \omega_{2}^{2}-\omega_{3}^{2} \leq 0.05, \omega_{1}^{2}-\omega_{2}^{2} \geq \omega_{5}^{2}-\omega_{4}^{2} \\
\omega_{1}^{2}+\omega_{2}^{2}+\omega_{3}^{2}+\omega_{4}^{2}+\omega_{5}^{2}=1
\end{array} .\right.
\end{aligned}
$$

Using the evaluation data of third stage in Section 3, the traditional LINMAP model based on the third-stage PPSQ data can be denoted as: 


$$
\begin{aligned}
& \min \left\{\lambda_{12}+\lambda_{23}+\lambda_{41}+\lambda_{43}\right\} \\
& \left\{\begin{array}{l}
0.658 \omega_{1}^{3}+0.406 \omega_{2}^{3}+0.632 \omega_{3}^{3}+0.564 \omega_{4}^{3}+0.738 \omega_{5}^{3} \geq h \\
\lambda_{12}+\left(-0.137 \omega_{1}^{3}-0.177 \omega_{2}^{3}-0.151 \omega_{3}^{3}-0.120 \omega_{4}^{3}-0.335 \omega_{5}^{3}\right) \geq 0 \\
\lambda_{23}+\left(-0.030 \omega_{1}^{3}-0.071 \omega_{2}^{3}-0.013 \omega_{3}^{3}-0.006 \omega_{4}^{3}-0.154 \omega_{5}^{3}\right) \geq 0 \\
\lambda_{41}+\left(-0.162 \omega_{1}^{3}-0.044 \omega_{2}^{3}-0.151 \omega_{3}^{3}-0.156 \omega_{4}^{3}+0.119 \omega_{5}^{3}\right) \geq 0 \\
\lambda_{43}+\left(-0.329 \omega_{1}^{3}-0.203 \omega_{2}^{3}-0.316 \omega_{3}^{3}-0.282 \omega_{4}^{3}-0.369 \omega_{5}^{3}\right) \geq 0 \\
\lambda_{12}>=0, \lambda_{23}>=0, \lambda_{41}>=0, \lambda_{43}>=0 \\
\omega_{1}^{3} \geq 0.15, \omega_{2}^{3} \geq 0.1, \omega_{3}^{3} \geq 0.1, \omega_{4}^{3} \geq 0.12, \omega_{5}^{3} \geq 0.15, \omega_{1}^{3} \leq 0.45, \omega_{2}^{3} \leq 0.2 \\
\omega_{3}^{3} \leq 0.25, \omega_{1}^{3} \geq 1.3 \omega_{2}^{3}, \omega_{2}^{3}-\omega_{3}^{3} \leq 0.05, \omega_{1}^{3}-\omega_{2}^{3} \geq \omega_{5}^{3}-\omega_{4}^{3} \\
\omega_{1}^{3}+\omega_{2}^{3}+\omega_{3}^{3}+\omega_{4}^{3}+\omega_{5}^{3}=1
\end{array}\right.
\end{aligned}
$$

The calculation results of Eqs (37) (39) are $\left(\omega_{1}^{1}, \omega_{2}^{1}, \omega_{3}^{1}, \omega_{4}^{1}, \omega_{5}^{1}\right)=(0.150,0.115,0.100$, $0.485,0.150),\left(\omega_{1}^{2}, \omega_{2}^{2}, \omega_{3}^{2}, \omega_{4}^{2}, \omega_{5}^{2}\right)=(0.150,0.100,0.250,0.225,0.275)$ and $\left(\omega_{1}^{3}, \omega_{2}^{3}, \omega_{3}^{3}, \omega_{4}^{3}, \omega_{5}^{3}\right)=$ $(0.150,0.115,0.100,0.485,0.150)$ respectively. Then, the comprehensive score of all projects are calculated, and the final ranking results of four projects in three stages are $A_{4} \succ A_{1} \succ A_{2} \succ A_{3}$, $A_{4} \succ A_{1} \succ A_{2} \succ A_{3}$ and $A_{4} \succ A_{2} \succ A_{3} \succ A_{1}$ respectively.

\subsection{Comparative analysis and summary}

Based on the dynamic PPSQ example analysis by use of the traditional LINMAP method and the new method, the results of ranking order are analyzed. The final results by using the two methods are summarized in Table 6.

Table 6. Summary of analysis results of PPSQ example

\begin{tabular}{|l|c|c|c|c|}
\hline & $t=1$ & $t=2$ & $t=3$ & $\begin{array}{c}\text { Comprehensive } \\
\text { ranking order }\end{array}$ \\
\hline $\begin{array}{l}\text { The new } \\
\text { method of } \\
\text { this paper }\end{array}$ & $A_{4} \succ A_{2} \succ A_{3} \succ A_{1}$ & $A_{4} \succ A_{1} \succ A_{2} \succ A_{3}$ & $A_{4} \succ A_{1} \succ A_{3} \succ A_{2}$ & $A_{4} \succ A_{1} \succ A_{2} \succ A_{3}$ \\
\hline $\begin{array}{l}\text { The traditional } \\
\text { LINMAP } \\
\text { method }\end{array}$ & $A_{4} \succ A_{1} \succ A_{2} \succ A_{3}$ & $A_{4} \succ A_{1} \succ A_{2} \succ A_{3}$ & $A_{4} \succ A_{2} \succ A_{3} \succ A_{1}$ & -- \\
\hline
\end{tabular}

Except that the project $A_{4}$ is the best choice of all ranking results, the other projects varies greatly in the different ranking results. By analyzing these different ranking results from the above table, the conclusions and their reasons are as follows:

1) The evaluation results of each stage are different from the comprehensive evaluation results. Since the traditional LINMAP method cannot simultaneously fuse the evaluation information of different stages, we discuss the evaluation results using the new method. Obviously, the ranking order in the first and third stages is not the same as the comprehensive ranking by using the new method of this paper. The reason is that the comprehensive results reflect data fusion of three stages. The method based on multi-stage data fusion effectively solves the problem of dynamic PPSQ evaluation. 
2) The evaluation results by the new method are different from those of the traditional LINMAP method. Except for the second stage, the ranking results of the comprehensive ranking based on the data of each stage are different. It reflects the difference between the two methods, and the new method is the improvement of the traditional LINMAP method. Furthermore, only the new method can process multi-stage data simultaneously, while not the traditional LINMAP method. It shows the advantages of the new method.

3) The comprehensive ranking order reflects the characteristics of these projects. The PSQ for all the projects ranked from the best to the worst: grand theater, museum, library and science museum. Combined with the field investigation, the reasons for the above ranking are analyzed as follows: The visitors in grand theater and museum are decent, and the property service pressure is low. Therefore, the PSQ is low. The proportion of youngsters' visitors in the library and science museum is high. Therefore, the PSQ is high.

\section{Conclusions}

This paper proposes a dynamic LINMAP model based on general MAMS matrix, and it is taken as a new method of PPSQ evaluation which suitable for multi-stage information fusion. On the one hand, the new method can effectively evaluation PPSQ based on complex information. The complexity of modern PPSQ evaluation is characterized by dynamic, heterogeneous and large-scale data. Dynamic LINMAP model is an extension of the classical LINMAP model. The information fusion method based on dynamic LINMAP model is an innovation of the PPSQ evaluation theory. On the other hand, using the dynamic LINMAP method to solve objective weights is the core of the new PPSQ method. The objective weights of the same attribute in different stages are not exactly the same. From Eqs (29) to (31), it can be seen that the objective weight of the same attribute changes at different evaluation stages, among which the weight of attitude and facilities changes greatly. The feasibility and stability of the new method are verified by an example analysis.

However, the threshold value is determined according to the experience of decisionmakers and the existing research results, and there is not enough quantitative research on how to determine the threshold value. This is a question worthy of further study. In addition, the new method can also be used for hotel, library, hospital, government and other service fields. The new method can further expand the application field in the future research.

\section{Acknowledgements}

This research is the development foundation project of Zhejiang College, Shanghai University of Finance and Economics (No. 2019GR006), the Key Program of National Natural Science Foundation of China (No.71231003) and the Social Science Planning Project in Zhejiang province (No. 19NDJC 396YBM). 


\section{References}

Anderson, R. E. (1973). Consumer dissatisfaction: the effect of disconfirmed expectancy on perceived product performance, Journal of Marketing Research, 10(1), 38-44.

https://doi.org/10.1177/002224377301000106

Bereketli, I., Genevois, M. E., Albayrak, Y. E., \& Özyol, M. (2011). WEEE treatment strategies' evaluation using fuzzy LINMAP method. Expert Systems with Applications, 38(1), 71-79. https://doi.org/10.1016/j.eswa.2010.06.015

Berry, L. L., Parasuraman A., \& Zeithaml, V. A. (1988). The service-quality puzzle. Business Horizons, 31, 35-43. https://doi.org/10.1016/0007-6813(88)90053-5

Bitner, M. J. (1990). Evaluating service encounters: The effects of physical surroundings and employee responses. Journal of Marketing, 54(2), 69-82. https://doi.org/10.1177/002224299005400206

Brown, T. J., Churchill, G. A., \& Peter, J. P. (1993). Improving the measurement of service quality. Journal of Retailing, 69(1), 127-139. https://doi.org/10.1016/S0022-4359(05)80006-5

Cai, C., Xu, X. H., Wang, P., \& Chen, X. H. (2016). A multi-stage conflict style large group emergency decision-making method. Soft Computing, 21(19), 5765-5778. https://doi.org/10.1007/s00500-016-2155-5

Cardozo, R. N. (1965). An experimental study of customer effort, expectation, and satisfaction. Journal of Marketing Research, 2(3), 244-249. https://doi.org/10.1177/002224376500200303

Chen, X. H. (2009). Complex large group decision-making and application. Science Press.

Cheng, L. S. (2011). Theory and method of service quality evaluation. China Standard Press.

China Property Management Institute. (2018). National property management industry development report 2018. China Property Management Institute, Beijing, China. http://www.ecpmi.org.cn/

Cronin, J. J., \& Taylor, S. A. (1992). Measuring service quality: A reexamination and extension. Journal of Marketing, 56, 55-68. https://doi.org/10.1177/002224299205600304

Deng, R. S. (2007). Analysis of the origin of property management, Modern Property, (04), 8-9.

Deng, J. J., \& Luo, L. (2006). Measurement of owner satisfaction in residential property management. Technology and Market, (09), 58-60.

Deng, J., Sheng, P. P., Wang, R., \& Shen, Y. (2018). An empirical research on the quality evaluation of archival websites from the perspective of user perception. Library and Information Service, 62(01), 33-39.

Erto, P., \& Vanacore, A. (2002). A probabilistic approach to measure hotel service quality. Total Quality Management, 13(2), 165-174. https://doi.org/10.1080/09544120120102405

Gou, X., Xu, Z., \& Herrera, F. (2018). Consensus reaching process for large-scale group decision-making with double hierarchy hesitant fuzzy linguistic preference relations. Knowledge-Based Systems, 157, 20-33. https://doi.org/10.1016/j.knosys.2018.05.008

Gronroos, C. (1983). Strategic management and marketing in the service sector (pp. 83-104). Marketing Science Institute. https://www.msi.org/reports/strategic-management-and-marketing-in-theservice-sector

Gronroos, C. (2000). Service management and marketing: A customer relationship management approach. Wiley.

Guo, H. L., \& Wang, Y. C. (2014). Performance evaluation model and application of project department of large-scale property service companies. China Journal of Commerce, (5), 56-58.

Razavi Hajiagha, S. H., Hashemi, Sh. S., Zavadskas, E. K., \& Akrami, H. (2012). Extensions of linmap model for multi criteria decision making with grey numbers. Technological \& Economic Development of Economy, 18(4), 636-650. https://doi.org/10.3846/20294913.2012.740518 
Han, L. J., Tang, X. Y, \& Tong, Z. Q. (2013). The quality evaluation of property service based on SERVQUAL model - a Nanjing city perspective. Journal of Engineering Management, 27(06), 56-60.

Hedvall, M. B., \& Paltschik, M. (1991). Developing pharmacy services: a customer-driven interaction and counselling approach. The Service Industries Journal, 11(1), 36-46. https://doi.org/10.1080/02642069100000004

Huang, G. L., \& Li, J. Z. (2013). Research on customer satisfaction evaluation of residential property management. China Economist, (06), 23-24.

Huo, Y. B. (2010). Study on service quality evaluation of property management based on SERVQUAL. Journal of Nanjing University of Finance and Economics, (02), 81-84.

Juran, J. M. (1986). The quality trilogy. Quality Progress, 9(8), 19-24. https://statmodeling.stat.columbia.edu/wp-content/uploads/2017/10/Juran-trilogy-1986.pdf

Ko, Y. J., \& Pastore, D. L. (2004). Current issues and conceptualizations of service quality in the recreation sport industry. Sport Marketing Quarterly, 13(3), 158-166.

Lehtinen, U., \& Lehtinen, J. R. (1982). Service quality: A study of quality dimensions (Working paper). Service Management Institute, Helsinki.

https://www.scirp.org/reference/ReferencesPapers.aspx?ReferenceID=2163317

Li, D. F. (2008). Extension of the LINMAP for multiattribute decision-making under Atanassov's intuitionistic fuzzy environment. Fuzzy Optimization \& Decision-Making, 7, 17-34. https://doi.org/10.1007/s10700-007-9022-X

Li, D. F., Chen, G. H., \& Huang, Z. G. (2010). Linear programming method for multiattribute group decision making using IF sets. Information Sciences, 180, 1591-1609. https://doi.org/10.1016/j.ins.2010.01.017

Li, D. F., \& Yang, J. B. (2004). Fuzzy linear programming technique for multiattribute group decisionmaking in fuzzy environments. Information Sciences, 158, 263-275. https://doi.org/10.1016/j.ins.2003.08.007

Li, J. M. (2010). SQ-Atten: Service quality evaluation approach of public sector's websites. Journal of Intelligence, 29(02), 72-79.

Liao, Q. Y., \& Hu, S. S. (2017). Research on the evaluation system of property management service quality for residential quarters: taking Chongqing as an example. Construction Economy, 38, 76-82.

Liu, H. Q., \& Liu, Q. (2012). Institutional arrangement and government role in home-based care services. Reform, (03), 66-71.

Liu, H. C., Li, Z., Zhang, J. Q., \& You, X. Y. (2018). A large group decision-making approach for dependence assessment in human reliability analysis. Reliability Engineering \& System Safety, 176, 135-144. https://doi.org/10.1016/j.ress.2018.04.008

Liu, L. J., \& Zuo, W. J. (2019). Interval value weighted Muirhead mean operator and its application in perceived service quality evaluation. Journal of Industrial Technological Economics, 38(05), 38-44.

Liu, Y., Yu, M., \& Liu, Y. (2019). Evaluation model of bus line service quality based on passenger perception. Journal of Northeastern University (Natural Science Edition), 40(05), 750-755.

Liu, Y., Fan, Z. P., \& Zhang, X. (2016). A method for large group decision-making based on evaluation information provided by participators from multiple groups. Information Fusion, 29, 132-141. https://doi.org/10.1016/j.inffus.2015.08.002

Liu, Y. (2003). Research on customer satisfaction evaluation. Social Sciences Academic Press.

Lo, K. K., Hui, E. C. M., \& Ching, R. H. F. (2013). Analytic hierarchy process approach for competitive property management attributes. Facilities, 31(1/2), 84-96. https://doi.org/10.1108/02632771311292536

Lu, Y. F. (2018). Application of QFD theory in improving the perceived quality of property service. Management and Administration, 409(7), 130-133. 
Lv, X. H., \& Li, D. F. (2004). Extension of LINMAP to group decision in the fuzzy environment. Systems Engineering \& Electronics, 26, 605-564. https://doi.org/10.1088/0256-307X/21/5/051

Mazis, M. B. (1975). Antipollution measures and psychological reactance theory: A field experiment. Journal of Personality \& Social Psychology, 31(4), 654-660. https://doi.org/10.1037/h0077075

Mesarovic, M. D., \& Takahara, Y. (1972). On a qualitative theory of satisfactory control. Information Sciences, 4(4), 291-313. https://doi.org/10.1016/S0020-0255(72)80018-5

Miao, Y. (2010). Study on the selection and ranking of factors influencing customer satisfaction of urban residential property based on key events. Journal of Changsha University, 24(6), 24-26.

Ming, J. R., \& Cao, H. Z. (2019). Research on evaluation of mobile library service quality based on grounded theory. Library Tribune, 39(08), 66-73.

Olshavsky, R. W., \& Miller, J. A. (1972). Consumer expectations, product performance, and perceived product quality. Journal of Marketing Research, 9(1), 19-21. https://doi.org/10.1177/002224377200900105

Parasuraman, A., Zeithaml, V. A., \& Berry, L. L. (1985). A conceptual model of service quality and its implications for future research. Journal of Marketing, 49(4), 41-50. https://doi.org/10.1177/002224298504900403

Podinovski, V. V. (2010). Set choice problems with incomplete information about the preferences of the decision maker. European Journal of Operational Research, 207, 371-379.

https://doi.org/10.1016/j.ejor.2010.04.010

Qin, Y. H., \& Liu, D. X. (2015). Research on urban residents'perception and evaluation of domestic tourism service quality in China. Journal of Southwest University (Natural Science Edition), 37(04), $47-54$.

Shiu, J. Y., Lu, S. T., Chang, D. S., \& Wu, K. W. (2016). Fuzzy multicriteria decision-making tools for selecting a professional property management company. International Transactions in Operational Research, 26(4), 1527-1557. https://doi.org/10.1111/itor.12356

Shi, L. (2017). Research on construction of evaluation index system of service quality perceived by express customers and influencing factors. Price: Theory \& Practice, (07), 149-152.

Shocker, A. D., \& Srinivasan, V. (1973). LINMAP: Linear programming techniques for the multidimensional analysis of preferences. Psychometrika, 38, 337-369. https://doi.org/10.1007/BF02291658

Wan, S. P., \& Li, D. F. (2013). Fuzzy LINMAP approach to heterogeneous MADM considering comparisons of alternatives with hesitation degrees. Omega, 41, 925-940. https://doi.org/10.1016/j.omega.2012.12.002

Wang, Z., Li, K. W., \& Wang, W. (2009). An approach to multiattribute decision making with intervalvalued intuitionistic fuzzy assessments and incomplete weights. Information Sciences, 179, 30263040. https://doi.org/10.1016/j.ins.2009.05.001

Weiner, B. (1986). An attributional theory of motivation and emotion. SSSP Springer, 92(4), 159-190. https://doi.org/10.1037/0033-295X.92.4.548

Wu, J. (2009). Application of SERVQUAL method in property service quality evaluation. Modern Property Management, (10), 78-81.

Song, W., Zhu, J. J., \& Zhang, S. T. (2018). A multi-stage uncertain risk decision-making method with reference point based on extended LINMAP method. Journal of Intelligent \& Fuzzy Systems, 35, 1133-1146. https://doi.org/10.3233/JIFS-17931

Xie, J. J. (2012). A superficial understanding of the transformation and upgrading of property management to modern service industry. China Property Management, (10), 8-9.

Xu, X. H., Du, Z. J., Chen X. H., \& Zhou, Y. J. (2017). Conflict large-group emergency decision-making method while protecting minority opinions. Journal of Management Sciences in China, 20, 10-23. 
Xu, X. H., \& Wu, H. D. (2014). A multi-attribute large group decision-making method based on fuzzy preference dynamic information interacting. Advances in Intelligent Systems and Computing, 281, 1423-1433. https://doi.org/10.1007/978-3-642-55122-2_122

Xu, X. H., Wang, M. S., \& Chen, X. H. (2014). Multi-attribute \& multi-stage large group decisionmaking method for preference conflict optimization. Journal of Systems Engineering, 29(01), 48-55.

Xu, Y. J., Wen, X. W., \& Zhang, W. C. (2018). A two-stage consensus method for large-scale multiattribute group decision making with an application to earthquake shelter selection. Computers \& Industrial Engineering, 116, 113-129. https://doi.org/10.1016/j.cie.2017.11.025

Xu, Y. J., Xu, A. W., \& Wang, H. M. (2016). Hesitant fuzzy linguistic linear programming technique for multidimensional analysis of preference for multi-attribute group decision making. International Journal of Machine Learning and Cybernetics, 7(5), 845-855. https://doi.org/10.1007/s13042-015-0417-7

$\mathrm{Xu}, \mathrm{Z}$. S. (2009). Multi-period multi-attribute group decision-making under linguistic assessments. International Journal of General Systems, 38(8), 823-850. https://doi.org/10.1080/03081070903257920

Xue, W. T., Xu, Z. S., Zhang, X. L., \& Tian, X. L. (2018). Pythagorean fuzzy LINMAP method based on the entropy theory for railway project investment decision making. International Journal of Intelligent Systems, 33(1), 93-125. https://doi.org/10.1002/int.21941

Yager, R. R. (1988). On ordered weighted averaging aggregation operators in multicriteria decision making. Systems, Man and Cybernetics, IEEE Transactions on, 18, 183-190. https://doi.org/10.1109/21.87068

Yang, G. X., \& Shen, S. (2012). Evaluation on the satisfaction of property services in urban residential areas. Research on Development, 158, 156-160.

Yao, H. H., \& Zhong, S. (2008). Effect of QFD on improvement of property management service quality. China Market, (13), 54-55.

You, T. H., Zhang, J., \& Fan, Z. P. (2017). Method for selecting desirable product(s) based on online rating information and customer's aspirations. Chinese Journal of Management Science, 25, 94-102.

Yu, G. F., Fei, W., \& Li, D. F. (2019). A compromise-typed variable weight decision method for hybrid multi-attribute decision making, IEEE Transactions on Fuzzy Systems, 27(5), 861-872. https://doi.org/10.1109/TFUZZ.2018.2880705

Zhang, Q. T., \& Cao, W. (2016). Study on the service quality evaluation system of modern distance education from the perspective of learners and managers. Distance Education in China, (10), 44-50.

Zhang, X., \& Fan, Z. P. (2011). A method for large group decision-making with multi-attribute and multi-identifier based on evidential reasoning. Operations Research and Management Science, 20, $15-20$.

Zhang, X., \& Fan, Z. P. (2014). A method for multi-attribute and multi-identifier large group decisionmaking based on prospect stochastic dominance. Control and Decision, 29, 1429-1433.

Zuo, W. J., Li, D. F., Yu, G. F., \& Zhang, L. P. (2019). A large group decision-making method and its application to the evaluation of property perceived service quality. Journal of Intelligent and Fuzzy Systems, 37(1), 1513-1527. https://doi.org/10.3233/JIFS-182934 